\title{
Experimental Study on the Combustion Characteristics of Deflagration and Pool Fire
}

\author{
Changyin Gao, Ling Yu, Wenxiang Cai, Yilin Lin \\ Nanjing University of Science and Technology, Nanjing 210000, China
}

\begin{abstract}
In the survey stage of nuclear power plant site, it is necessary to consider the impact on nuclear power station brought by the aircraft. The most serious consequence is the fuel leak. The fuel combustion process is divided into two stages of deflagration and pool fire. Therefore, this paper studies the deflagration and pool fire combustion and its mechanism, the evaporation rate of aviation kerosene and Simulated Reactor gas surface temperature and pressure changes. The results show that flame will quickly generate pressure shock wave in the stage of deflagration. It will have a huge impact on buildings. Its instantaneous high temperature also has a large thermal load on the building through the radiation, convection and other forms.
\end{abstract}

KEYWORD: evaporation rate of aviation kerosene, pool fires, pressure

\section{INTRODUCTION}

As a kind of new important energy to alleviate the global energy crisis and climate change, Nuclear power has been widely ultilized in many countries around the world. So far, there are more than 30 countries to build and operate the National Nuclear Power Station. Nuclear power accounts for $15 \%$ of the world's total output value of electricity ${ }^{[1]}$. "Safety" is the lifeline of nuclear power. The development of nuclear power in China must be based on security. Nuclear power plant in decades of operating experience shows that the fire has a great potential threat to the safety of nuclear power plants. The possibility of fire runs through in the whole life of nuclear power plant from the designing stage to the last stage of decommissioning. ${ }^{[2]}$

In the stage of prospecting the sites of power plants, it is necessary to consider the impact on nuclear power station brought by the aircraft. Among them, the consequences of leakage of fuel on aircraft is the most serious. According to the distribution of the fuel and the state, it may cause some or all the fuel burning. Generally, it can be divided into deflagration and pool fire. In the deflagration stage, the flames quickly forms a pressure shock wave. It has a great shock to the building. Its instantaneous high temperature also has a large thermal load on the building through the radiation, convection and other forms. In the pool fire stage, the stable and continuous combustion will transfer a lot of heat to the reactor shielding plant through convection, heat radia- tion and other forms. So it will cause the significant reduction of the relevant parts of the structural strength. V.Babrauska ${ }^{[3]}$ got the rate prediction model of aviation kerosene pool fire combustion smoke free combustion. Sun Zhiyou studied the characteristics of aviation kerosene pool fire and obtained the characteristics of flame combustion under the condition of fire ${ }^{[4]}$. At present, there are few studies on the influence of high temperature gas and pressure wave on the formation of combustion. The depth of the study should be further strengthened.

This paper ultilizes high frequency infrared thermal imaging system ${ }^{[5]}$, pressure sensor, temperature sensor and data acquisition and processing system in order to simulate the combustion process of the reactor in the fire.

\section{EXPERIMENTAL RESEARCH OBJECT AND METHOD}

\subsection{Experimental Research Object.}

The laboratory bench is composed of three parts, which are square oil pool, test system, data acquisition and processing. In this paper, it is based on the ISO9705 full size heat release rate laboratory bench. It sets up the experimental platform of the pool fire with wind conditions. Figure 1 and Figure 2, the length (L) are $1210 \mathrm{~mm}, 1210 \mathrm{~mm}, 200 \mathrm{~mm}$. The fuel is kerosene. It is required to put the pan on the electronic balance before the experiment that used to calculate the reduced mass of aviation kerosene ${ }^{[6]}$. 


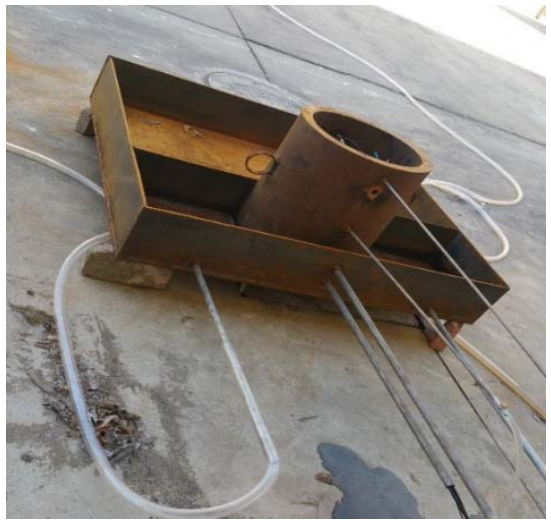

Fig. 1 Experimental platform

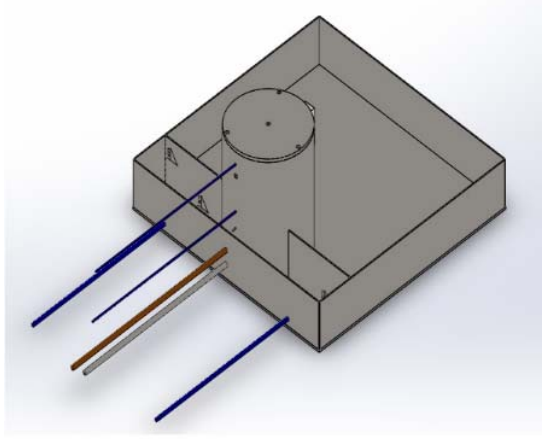

Fig. 2 Three dimensional model

\subsection{Experimental Methods.}

In the experiment, the aviation kerosene in the oil pool is firstly used in the oil pool. A container with appropriate aviation kerosene is arranged in the oil tank. The fire caused by the pool of fire burning forms a high temperature. Heating container of aviation kerosene can evaporate and increase the pressure in the vessel ${ }^{[7]}$. When reached the limiting value of explosion vessel, it will cause deflagration phenomenon.

Two high frequency water cooling pressure sensors are installed at the 2/3 height and 1/4 height of the reactor. A thermocouple is installed at the height of $4 / 5$. Because of high gas deflagration temperature of $800^{\circ} \mathrm{C}$, we choose Kistler-7061B high-precision water-cooling piezoelectric type pressure sensor, which is used to measure gas pressure fluctuation. The effective range of pressure is $0-15 \mathrm{Mpa}$ and sensitivity is $-822 \mathrm{pc} / \mathrm{MPa}$. In addition, we choose the high temperature $\mathrm{K}$ thermocouple ${ }^{[8]}$ used to measure the temperature of the surface of the simulation reaction. The effective range of tempeature measurement is $0-1200{ }^{\circ} \mathrm{C}$.

Data acquisition system ${ }^{[9]}$ is composed of industrial control computer, monitor, data acquisition card [10], test software, 24V DC transformer, power supply and so on.

\subsection{Fuel Evaporation Rate.}

In this paper, the natural evaporation rate of aviation kerosene is measured by the precise electronic balance with accuracy of $0.01 \mathrm{~g}$. The evaporation surface area of the container is $0.115 \mathrm{~m} \times 0.085 \mathrm{~m}$. The time of calculation is 540s. The natural evaporation rate ${ }^{[11]}$ of the experimental results is $0.6555 \mathrm{~g} / \mathrm{m}^{2} / \mathrm{s}$. The temperature of the experiment was $8^{\circ} \mathrm{C}$. Relative humidity is $25 \%$. Under the same conditions, the fuel evaporation rate of the combustion state is $3.881 \mathrm{~g} / \mathrm{m}^{2} / \mathrm{s}$.

\subsection{Pressure and Temperature Measurement.}

Figure 3 shows the positions of each measurement point when ultilizing the infrared thermographer to measure the temperature of flame. Among them, 1 3 stand flame temperature, 4 stands the temperature of side wall of oil pool.

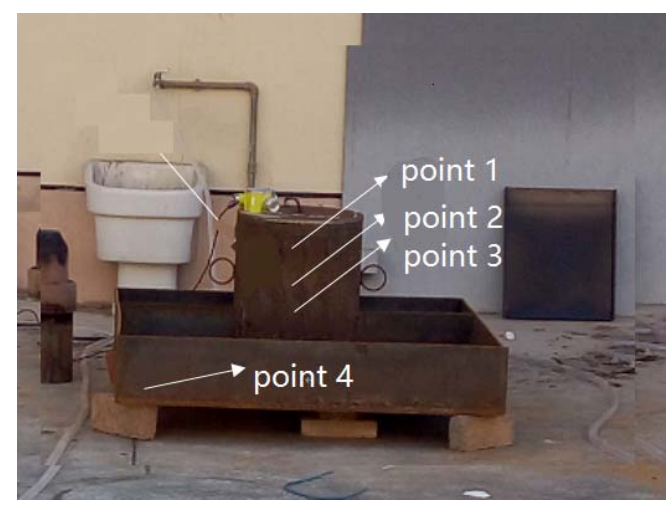

Fig. 3 Measuring point

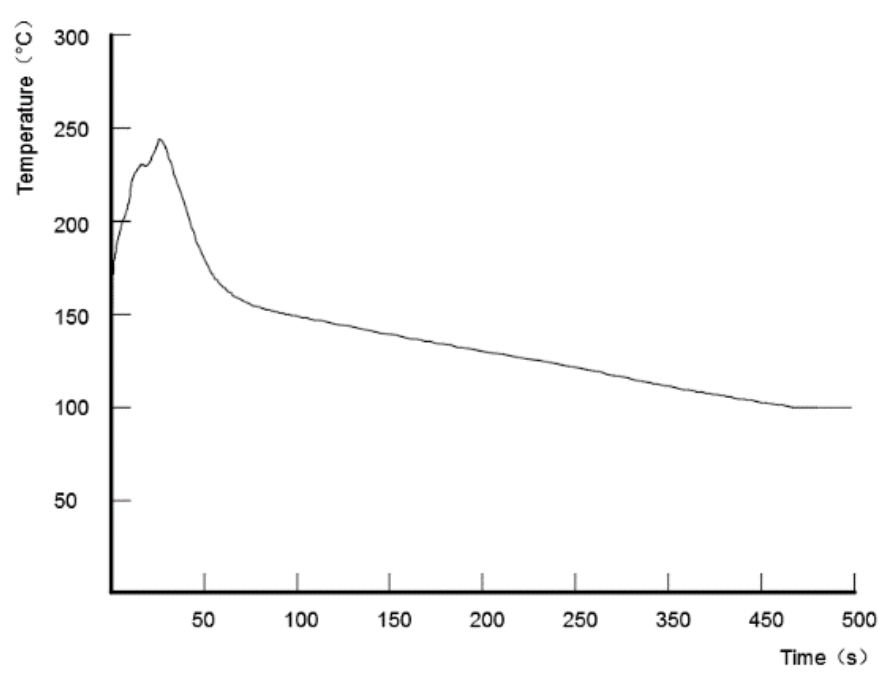

Fig. 4 Gas temperature near the wall

As shown in figure 4, the flame temperature of the $2 \mathrm{~mm}$ at the wall of the reactor is changing with time. In approximate windless, as the burning continues, the oxygen at the top of oil tank consumed. External 
oxygen does not promptly add to the combustion zone. The fuel's combustion efficiency decreases rapidly, so the temperature measuring gas temperature decreased slowly.

Figure 5 is the change law of pressure at the temperature measurement point 1 under the pressure of the $0.08 \mathrm{~m}$. The peak pressure is about $0.7 \mathrm{Mpa}$. At the peak of the pressure, the fuel pressure in the container reaches the extreme value. It will explode and burn.

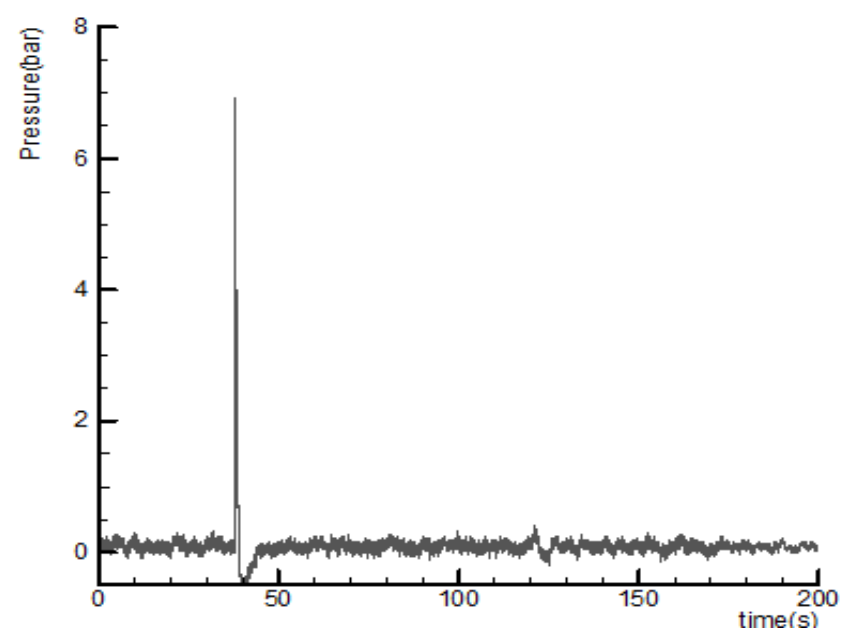

Fig. 5 Gas pressure

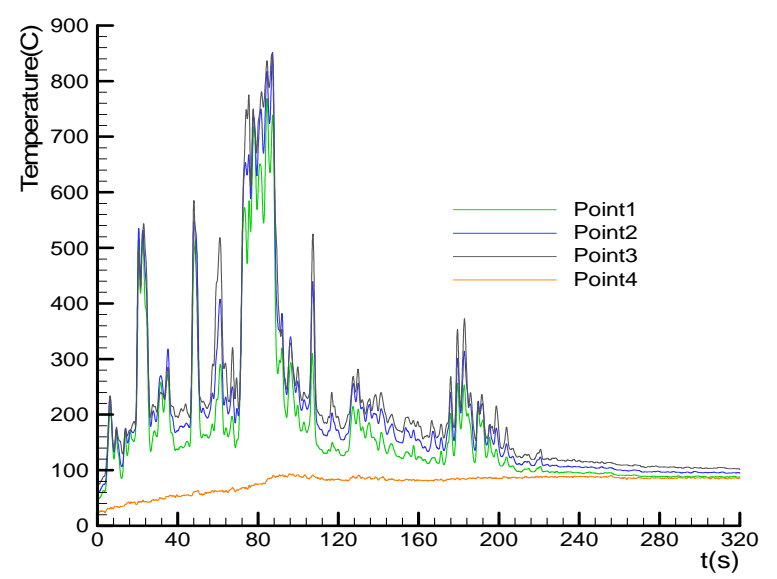

Fig. 6 Infrared imager value

Figure6 is the change of the temperature of each measuring point with time. It can be known that the flame temperature obtained by the experiment is close to the external environment due to the working characteristics of the infrared thermal imaging system. The fuel is fully burnt at the point 1 to 3 . The maximum temperature is higher than that of the gas temperature near the wall of the simulated reactor. The temperature of point 4 on the side wall of the oil pool increases with the increase of time. But when the combustion is stable, the temperature is kept at $100^{\circ} \mathrm{C}$. It is indicated that the pool fire combustion is stable and has the relative representation.

\section{SUMMARY}

This paper describes the measurement of the reactor in the simulation of pool fire and explosion combustion parameters such as temperature and pressure. Through the above research, the following conclusions can be drawn:

1 The fuel evaporation rate is about 6 times of natural evaporation rate.

2 In windless conditions, the combustion process is the diffusion combustion and related to the oxygen concentration. In the simulation of the reactor surface, due to the lack of oxygen, in addition to the beginning stage of the temperature is higher, the other temperature should be lower than the gas temperature away from the simulation reactor.

3 The experimental results show that the detonation combustion duration is very short, only about $10 \mathrm{~ms}$. High temperature and pressure gas rapidly dissipate in the deflagration occurred. It has little effect on the surface of buildings.

\section{ACKNOWLEDGEMENTS}

The authors gratefully acknowledge the financial support of Project 51306092 supported by National Natural Science Foundation of China, "Mechanism research of pulse combustion and its pollution emission". The authors would also like to thank the reviewers for their valuable comments and suggestions.

\section{REFERENCES}

[1] Rogers K A, Fire in the hole: A review of national spent nuclear fuel disposal poliy, J. progress in Nuclear Energy, (2009), 51[2]:281-289.

[2] IEAE, Experience Gained from Fires in Nuclear power plants: Lessons Learened, R.USA International Atomic Energy Agency. (2004).

[3] V Babransks, The SFPE Hand book of Fire Protection Engineering, 2nd, M. Massachusetts: National Fire Protection Association, (1995); 251-261.

[4] Sun Zhiyou, Study on combustion characteristics of aviation kerosene pool fire.D. University of Science and Technology of China, HeFei, (2008).

[5] Shi Sansheng, Building and Proficiency Testing of Calibration Device for Temperature Measurement Accuracy of Thermal Imager, State Grid Henan Electric Power Research Institute, Zheng Zhou 450052, China, (2016).

[6] Ni Jiadi, Effect of ventilation on the burning rate of aviation kerosene pool fire in a long and narrow space, J. Journal of Safety and Environment, University of Science and Technology of China, HeFei, (2010).

[7] ZHANG Jihong; NIE Chengnan, Numerical simulation of fuel oil leakage of a crashed passenger plane, College of Aeronautical Automation, Civil Aviation University of China; (2013). 
[8] Wang Zhensen, Precise Calibration Furnace for Sheathed Thermocouples, J, Process Automation Instrumentation, (2012).

[9] Li Da, The Design \& Realization of Data Acquisition System Based on LabVIEW, J, China Instrumentation, (2007).

[10] Li Zongli, A Method for Measuring Synchronous Signal of Engine Based on NI Acquisition Card, J, Automobile Applied Technology, (2015)

[11] Zhang Shuo, CFD simulation on burings rates and radiation distribution of open pool fires, J., Fire Science and Technology. (2011). 